\title{
Comparison of Factors Related to Elderly People's Purpose of Life in Japan and Thailand
}

\author{
Takashi Ohue', Darunee Rujkorakarn², Amorn Suwannimitr², Supaporn Aryamuang², \\ Nongyaow Meethien ${ }^{2}$ \\ ${ }^{1}$ Department of Nursing, Faculty of Health Science, Hyogo University, \\ Kakogawa-Shi, Japan \\ ${ }^{2}$ Faculty of Nursing, Mahasarakham University, Maha Sarakham Province, Thailand \\ Email: ohue@hyogo-dai.ac.jp
}

Received 21 September 2015; accepted 18 October 2015; published 21 October 2015

Copyright (C) 2015 by authors and Scientific Research Publishing Inc.

This work is licensed under the Creative Commons Attribution International License (CC BY). http://creativecommons.org/licenses/by/4.0/

(c) (i) Open Access

\begin{abstract}
Purpose: In the present study, the features of "purpose of life" of elderly persons in Japan and Thailand are clarified by focusing on this concept and its related factors, and through the comparison of the results of Japan and Thailand. Methods: The Japanese subjects consist of the elderly aged 60 or older. The Thai subjects consist of the elderly aged 60 or older who live in Thailand. A sum of 250 subjects (men and women) per country will be studied. They were asked about their individual attribution and maintenance of healthy condition. Moreover, 19 items were examined as events leading to life purpose. These items were measured using the Philadelphia Geriatric Center Morale Scale, General Health Questionnaire (GHQ) and Instrumental Activities of Daily Living (IADL). Results: Data from 200 elderly people (male: 67, female: 133) in Thailand and 234 elderly people (male: 49, female: 185 ) in Japan were used in the analysis. Regarding an "Events Leading to Life Purpose," it was suggested that "activities to enhance learning and culture" and "neighbors and friends, and socializing with acquaintances" helped both in Japan and Thailand. Moreover, "elderly persons' club activities" and "child" were effective in Thailand, while "spouse" and "grandchild" were effective in Japan. Moreover, Model 1 (event, disease $\rightarrow$ purpose of life $\rightarrow$ mental health, and IADL) that became purpose of life for both countries was adopted. Conclusion: In order to improve older adults' mental health and ADL by improving "purpose of life", it is required to increase the events leading to life purpose and to prevent illness for both countries. In particular, "activities to enhance learning and culture" and "neighbors and friends, and socializing with acquaintances" was the activity which raises "purpose of life". Then, "elderly persons' club activities" and "child" were effective in Thailand, while "spouse" and "grandchild" were effective in Japan.
\end{abstract}


Keywords

\section{International Comparison (Japan, Thailand), Purpose of Life, Elderly People}

\section{Introduction}

Currently, there is a significant demographic revolution of global aging. Until now, countries around the world may have faced an aged society on some level, but not to the same extent as Japan. However, the increasing average age of populations is occurring in all areas of Southeast Asia, particularly those considered affluent-such as Singapore, South Korea, Thailand, and China — which are expected to become aged societies by 2050. Countermeasures for aging are currently considered a significant issue throughout all of Asia [1]. Among these countries is Thailand where the current average life expectancy is considered to be at the same level of Japan 30 years ago, but where there is a faster rate of aging, with $14 \%$ of the population expected to be aged 65 years or older by 2023. It will then be considered an aged society [2].

Help Age International presented the Global Age Watch Index 2014 [3], which was an online study seen as the first clear indication of how happy the elderly themselves are in society. Japan's ranking was 9th place, while its health ranking was 1st place; this is because it has the highest life expectancy and healthy life expectancy in the world. However, at the same time, the survey asked about "purpose of life" and a low response of 87.8 was received. In the 2013 investigation, Japan's health ranking was 5th place with the "purpose of life" item having an effect on this. Conversely, in Thailand, "purpose of life" was at 94.7, despite the country being ranked overall in36th place. In Thailand, social security and government interventions are considered the lowest out of all Southeast Asian countries [4]. Why then is the "purpose of life" for elderly persons higher in Thailand compared to Japan?

Age and level of happiness are assumed to follow a U curve according to studies from various foreign countries. To some degree, when people age, their level of happiness falls as they must give up their ambitions that they had when they were younger. Their level of happiness may again rise as they make the effort to change their way of thinking and to enhance their life from that point on; however, in Japan, the level of happiness does not rise even if entering a senile state [5].

Thus, the level of happiness of elderly persons in Japan tends to be lower compared to other countries and this is a significant problem as the number of elderly persons in Japan increases. Previous studies have looked at "purpose of life" of elderly persons in Italy, San Marino, France, Taiwan, Korea [6], Denmark [7], and the United States [8]. Meanwhile, Takahashi describes the concept of the "purpose of life" in Japan as comparable to that of the "purpose of life" in Italy, France, Denmark, the United States, Singapore, Taiwan, South Korea, and China [9]. "Independence," "family ties," and "associations" (groups of individuals participating with a purpose) are considered a part of this. However, no comparative study of Japan and Thailand has been undertaken thus far.

The concept of "purpose of life" in the Japanese language has a factor structure similar to a subjective, happy feeling overseas [10]-[13]. In the present study, the features of "purpose of life" of elderly persons in Japan and Thailand are clarified by focusing on this concept and its related factors, and through the comparison of the results of Japan and Thailand. These findings could potentially improve the "purpose of life" of elderly persons in both countries.

\section{Definition of Terms}

Definitions of "purpose in life" vary depending on the researcher. Hasegawa's definition classified "purpose in life" into "Events Leading to Life Purpose" and "Sense of Purpose in Life." [14] This is used in the present study to compare Japan and Thailand. The "Events Leading to Life Purpose" for the two countries became clear according to this classification. Hasegawa noted that "realize that one is alive now here, individual consciousness to be alive motives" and "purpose in life" is defined as the components of a "life worth living." When the question was asked, "is your life worth living," that person's past experience and current events are visualized in mind, there is a "life worth living target,"“future of the image, self-realization, and willingness to come". Additionally, life fulfillment, life motivation, survival feeling, sense of stability, efficacy (helplessness), variety of a 
driving sense of emotion, and the self with independence that integrates with the "Sense of Purpose in Life." The concept as overall been defined as consists of the function of the psychology.

\section{Methods}

\subsection{Investigation Period}

The investigation was undertaken in Japan and Thailand from September 2014 to November 2014.

\subsection{Sample}

In Japan, participants were 250 elderly persons aged 60 years or over who had attended the meeting of elderly persons held in city A's public hall. In Thailand, participants were 250 elderly persons aged 60 years or over who lived in Thailand's B district. Elderly persons in Thailand are defined as aged 60 years or over; therefore, those aged 60 years or over in Thailand and Japan were recruited.

\subsection{Recruitment Method}

In Japan, the questionnaires were distributed at the public hall in city A; it was requested that they be returned to the recovery box. In Thailand, the research representative mentioned the forthcoming study in the place where elderly persons in B district gathered, with cooperation from the university's Faculty of Nursing in Thailand. In both countries, the meaning of the present study, implementation, protection of personal information, ethics, and so forth were explained when consent had been obtained.

\subsection{Evaluation Index}

The assessment index measures elderly persons' "purpose of life” and related factors; this assessment index is used worldwide.

1. Personal factors associated with "purpose of life" in the elderly: Age, family structure, maintenance of healthy condition, living arrangements, and presence or absence of intergenerational exchange were asked.

2. Event becomes a reason for living: Hasegawa et al. [15] determined the following: 1) work; 2) activities to enhance learning and culture; 3) sports and recreational activities; 4) hobby activities; 5) volunteer activities; 6) elderly persons' club activities; 7) neighbors and friends, and socializing with acquaintances; 8) care of grandchild, and family reunion; 9) going out for shopping and travel; 10) activities, such as residents' association; 11) accumulated knowledge and technology; 12) spouse; 13) children; 14) grandchildren; 15) health; 16) pet; 17) role in the home; 18) role in society; and 19) other.

3. Measurement of "purpose of life": A shortened version of the Philadelphia Geriatric Center (PGC) Morale Scale was used [16]. A Japanese edition was confirmed by Okuzumi et al. [17]. Each question was answered as either "Yes" or "No"; the Sum score was 11 points. Meanwhile, Question 11 was divided into "agitation," "lonely dissatisfaction," and "attitude toward own aging."

4. Measurement of mental health: The General Health Questionnaire-12 (GHQ-12), developed by Goldberg and Williams [18], was used. Niiro and Mori established its validity and reliability in Japan [19]. Validity and reliability in Thailand were confirmed by Nilchaikovit et al. [20]. This scale comprised 12 items, and each item was rated using a 4-point scale. The answers were subsequently described. It was assumed that there would be a problem of a high score for mental health.

5. Measurement of IADL (Instrumental activities of daily living): Lawton s' scale was used [21]. It comprises eight items, including use the telephone, shopping, doing laundry, preparation of meals, housekeeping, using transportation, taking medicine, and home finances. A stepwise approach of four items was set for three to each item; it was assumed that the lower the number, the higher the degree of autonomy. An independent state for all items was allocated from 0 to 8 points; when all items were not independent, 0 points were given.

\subsection{Procedures}

The abovementioned scales were used for those who agreed to participate. In Japan, the original Japanese scale 
was used. In Thailand, the scale that was translated from English into Thai by the nursing science researcher was used. In Japan, the questionnaire was distributed and recovered in the public hall; in Thailand, the research representative requested the research from the senior university in Thailand.

\subsection{Analytical Method}

1) The scores of an individual attributes and conditions was calculated according to each country.

2) The factors of Japan and Thailand and man and woman were used to examine the differences of the "purpose of life" between the two countries and according to sex. Two-way ANOVA (Analysis of variance) was used to assume the subordinate in the scale that measured the autonomous variable with "purpose of life" as the dependent variable.

3) The factors of Japan and Thailand and presence of an event that became a "purpose of life" were used to examine the difference between the "event" and the "purpose of life" that became "purpose of life" in Japan and Thailand. Two-way ANOVA to assume the subordinate in the scale that measured the autonomous variable with "purpose of life" as a dependent variable was undertaken.

4) There was a comparative study of Model 1 (event, disease $\rightarrow$ purpose of life $\rightarrow$ mental health, and IADL) and Model 2 (event, disease $\rightarrow$ mental health, and IADL $\rightarrow$ purpose of life) to examine the model that influenced elderly persons' "purpose of life" for Japan and Thailand (Figure 1). Goodness of Fit Index (GFI), Adjusted Goodness of Fit Index (AGFI), and Root Mean Square Error of Approximation (RMSEA) were used. Goodness of fit was assessed with Akaike's information criterion (AIC), and a comparison of the models was undertaken (Figure 1). The Simultaneous Analysis of Several Groups was undertaken so that it might comparatively study the models for both the Japanese and Thai populations. Statistical significance was set at $p<0.05$.

\subsection{Ethical Considerations}

This study was conducted after obtaining approval from the ethical review board of the Hyogo University. We submitted written and verbal requests regarding participation to those in charge at the institutions where the study was conducted. After obtaining approval from the institutions, we explained the study to those who were approached to participate, both verbally and in writing, and then undertook the study only with those individuals who provided consent to participate. The consent form for the participants included the following: refusal to participate or withdrawal from participation in the study is voluntary and will not in any way disadvantage the participants, and the data obtained will be used only for this study. The following was also explained to the participants: the data would be handled statistically using a code number, protection of personal privacy would be guaranteed, and personal information would not be identifiable.

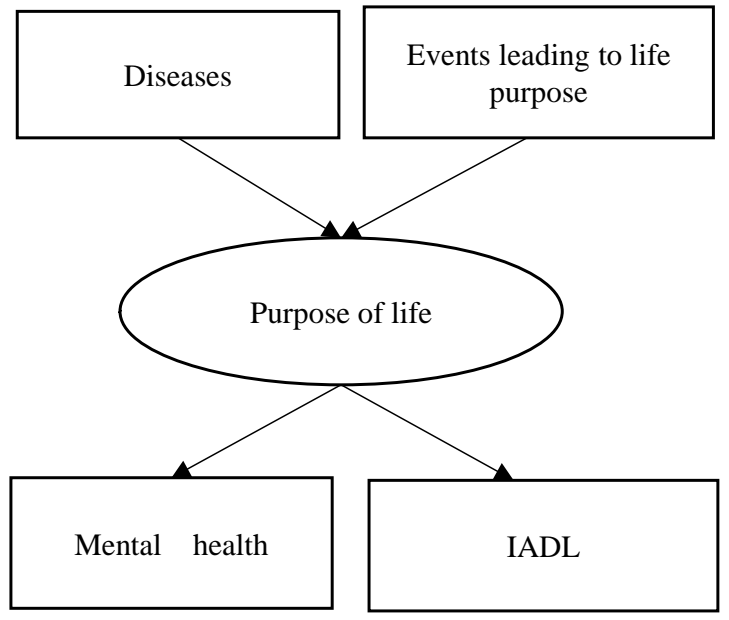

Model 1

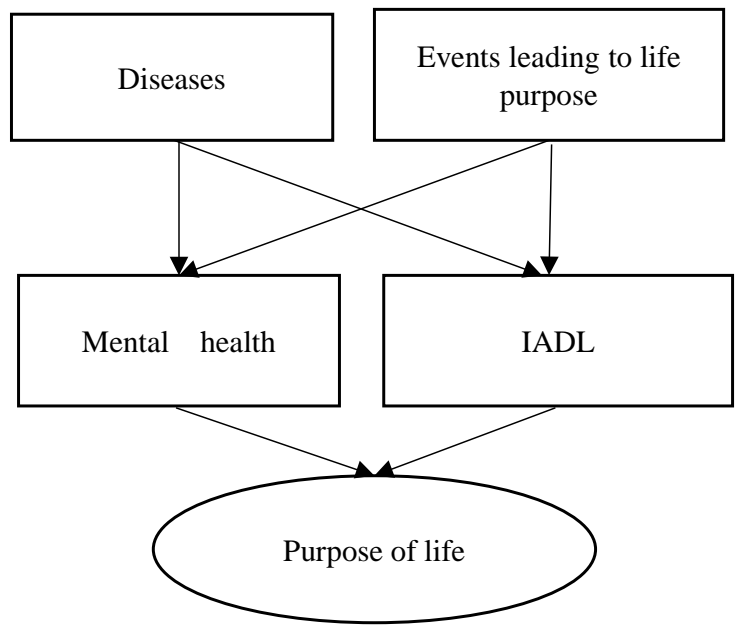

Model 2 


\section{Results}

The questionnaires were given to 500 people aged 60 or over in Thailand $(n=250)$ and Japan $(n=250)$. A sum of 244 responses were received in Japan. The outlier and missing values were omitted, resulting in 234 valid responses (49 men, 185 women) for 93.6\% valid response rate. A sum of 210 responses were received in Thailand. The outlier and the missing values were omitted, resulting in 200 valid responses (67 men, 133 women) for $80.0 \%$ valid response rate.

\subsection{Base Attributes and Condition of Participants by Country}

Regarding age, Japan was $72.74 \pm 5.87$ years, and Thailand was $69.28 \pm 7.10$ years. This was classified into the “young elderly" (60 - 74 years old) and the "latter-stage elderly” (75 years old or over). In Japan, there were 154 young elderly (65.81\%) and 80 latter-stage elderly (34.19\%). In Thailand, there were 162 young elderly (81.00\%) and 38 latter-stage elderly (19.00\%).

34 people (14.50\%) in Japan and 15 (7.50\%) in Thailand were "a couple and single child "as the family structure; 21 people (9.00\%) in Japan and 5 (2.50\%) in Thailand had “me and single child”. In Japan, 97 people (41.50\%) responded "spouse with two livelihoods" compared to 26 people (13.00\%) in Thailand; for “one-person household," there were64 people (27.40\%) in Japan and $22(11.00 \%)$ in Thailand. Eight people (3.40\%) in Japan and 112 (56.00\%) in Thailand responded "three-person household.”Seven people (3.00\%) in Japan and 20 (10.00\%) in Thailand were recorded under "others."

A sum of 191 people (81.60\%) inJapanand183 (91.50\%) in Thailand responded “One’s own house detached house” in Japan for resident status; 24 people (10.30\%) in Japan and three (1.50\%) in Thailand responded “condominium." Seven people (3.00\%) in Japan and 10 (5.00\%) in Thailand responded "rental unit and apartment."Four people (1.70\%) in Japan and four (2.00\%) in Thailand responded “Housing Corporation's apartment."Five people (2.10\%) in Japan and zero (0.00\%) in Thailand responded “other.” For "Yes,” 132 people (56.40\%) responded in Japan that there was a "presence of exchange between generations" compared to 132 $(66.00 \%)$ in Thailand.

Twenty people (8.50\%) in Japan and 24 (12.00\%) in Japan responded "very healthy (confident health)” in Thailand. "Much illness or disabilities; without such, living normally” received 143 responses (61.10\%) in Japan and 45 (22.50\%) in Thailand. "Although there is illness or disability, in daily life, can live normally, including going out can also be alone” received 61 responses (26.10\%) in Japan and 122 responses (61.00\%) in Thailand. "There was a disease or an obstacle, and it was almost oneself; could perform task in the house, but going out alone was not possible" received two responses (0.90\%) in Japan, and six (3.00\%) in Thailand. "There is an illness or disability, also necessary to help someone in life; even during the day, bed (futon) life is at the center” received one response $(0.40 \%)$ in Japan and three responses $(1.50 \%)$ in Thailand. In "there is illness or disability that requires assistance to be on top of the bed (futon) for one day," each country received zero responses (Table 1).

\subsection{The Difference between Sense of Purpose in Life by Country and Sex}

In order to examine the difference between Japan and "purpose in life” according to sex in Thailand, a two-way ANOVA was performed with country and sex as independent variables and the subscale that measures sense of purpose in life as the dependent variable (Table 2). The interaction of "agitation," $(F[1,430]=6.93, p<0.01)$, “lonely dissatisfaction” $(F[1,430]=4.28, p<0.05)$, and "Sum” $(F[1,430]=6.08, p<0.05)$ was significant.

Next, when each simple main effect was examined, a significant difference was found between Japanese men and women in "agitation" $(F[1,430]=8.53, p<0.05)$. In "lonely dissatisfaction," a significant difference was found between Thai men and women $(F[1,430]=5.12, p<0.05)$. A significant difference was found between Japanese men and women for the "Sum" $(F[1,430]=6.08, p<0.05)$. Meanwhile, a significant difference was found for "attitude toward own aging” ( $p<0.01)$, “agitation” $(p<0.01)$, "lonely dissatisfaction” $(p<0.05)$, and "Sum” $(p<0.01)$ in the main effect of classification by country.

\subsection{Difference between Event and "Purpose of Life" That Becomes "Purpose of Life" by Country}

The factors of Japan and Thailand and the presence of a disease were used to examine the difference between 
Table 1. Base attributes and condition of participants by country.

\begin{tabular}{|c|c|c|c|c|c|}
\hline \multirow[b]{2}{*}{ Gender } & & \multicolumn{2}{|c|}{ Japan } & \multicolumn{2}{|c|}{ Thailand } \\
\hline & & $\mathrm{N}$ & (\%) & $\mathrm{N}$ & (\%) \\
\hline & Men & 49 & 20.90 & 67 & 33.50 \\
\hline & Women & 185 & 79.10 & 133 & 66.50 \\
\hline
\end{tabular}

Age

Young elderly (60 - 74 years old)

Atter-stage elderly (75 years old or over)

Family structure

$\begin{array}{llll}154 & 65.81 & 162 & 81.00 \\ 80 & 34.19 & 38 & 19.00\end{array}$

$\begin{array}{llll}34 & 14.50 & 15 & 7.50 \\ 21 & 9.00 & 5 & 2.50 \\ 97 & 41.50 & 26 & 13.00 \\ 64 & 27.40 & 22 & 11.00 \\ 8 & 3.40 & 112 & 56.00 \\ 7 & 3.00 & 20 & 10.00\end{array}$

Residence status

$\begin{array}{llll}191 & 81.60 & 183 & 91.50 \\ 24 & 10.30 & 3 & 1.50 \\ 7 & 3.00 & 10 & 5.00 \\ 4 & 1.70 & 4 & 2.00 \\ 5 & 2.10 & 0 & 0.00\end{array}$

Presence of exchange between generations

$\begin{array}{llll}132 & 56.40 & 132 & 66.00 \\ 60 & 25.60 & 68 & 34.00\end{array}$

Health condition

Very healthy (confident health)

Much illness or disabilities; without such, living normally

Although there is illness or disability, in daily life, can live normally, including going out can also being alone

There was a disease or an obstacle, and it was almost oneself; could perform task in the house, but going out alone was not possible

There is an illness or disability, also necessary to help someone in life; even during the day, bed (futon) life is at the center

$\begin{array}{llll}20 & 8.50 & 24 & 12.00 \\ 143 & 61.10 & 45 & 22.50 \\ 61 & 26.10 & 122 & 61.00 \\ 2 & 0.90 & 6 & 3.00 \\ 1 & 0.40 & 3 & 1.50 \\ 0 & 0.00 & 0 & 0.00\end{array}$

There is illness or disability that requires assistance to be on top of the bed (futon) for one day 
Table 2. The comparative of "purpose of life” by country exception and gender.

\begin{tabular}{|c|c|c|c|c|c|c|c|c|c|c|c|}
\hline & \multicolumn{4}{|c|}{ Japan } & \multicolumn{4}{|c|}{ Thailand } & \multirow{3}{*}{$\begin{array}{c}\text { Main effect } \\
\text { (in Japan } \\
\text { and Thailand) } \\
\text { F }\end{array}$} & \multirow{3}{*}{$\begin{array}{c}\begin{array}{c}\text { Main } \\
\text { effect } \\
\text { (events) }\end{array} \\
\text { F }\end{array}$} & \multirow{3}{*}{$\begin{array}{c}\text { interaction } \\
\text { F }\end{array}$} \\
\hline & \multicolumn{2}{|c|}{$\begin{array}{c}\text { Men } \\
(\mathrm{N}=24)\end{array}$} & \multicolumn{2}{|c|}{$\begin{array}{l}\text { Woman } \\
(\mathrm{N}=210)\end{array}$} & \multicolumn{2}{|c|}{$\begin{array}{c}\text { Men } \\
(\mathrm{N}=26)\end{array}$} & \multicolumn{2}{|c|}{$\begin{array}{l}\text { Woman } \\
(\mathrm{N}=174)\end{array}$} & & & \\
\hline & $\mathbf{M}$ & SD & $\mathbf{M}$ & SD & $\mathbf{M}$ & SD & $\mathbf{M}$ & SD & & & \\
\hline Attitude toward own aging & 3.06 & 1.42 & 2.90 & 1.42 & 2.13 & 1.36 & 2.34 & 1.35 & $23.91^{* *}$ & 0.02 & 1.41 \\
\hline Agitation & 4.71 & 1.70 & 3.96 & 1.78 & 3.39 & 1.42 & 3.56 & 1.43 & $23.51^{* *}$ & 2.69 & $6.93^{* *}$ \\
\hline Lonely dissatisfaction & 4.98 & 1.28 & 4.82 & 1.42 & 4.33 & 1.57 & 4.79 & 1.23 & $5.05^{*}$ & 0.97 & $4.28^{*}$ \\
\hline Sum & 12.76 & 3.60 & 11.68 & 3.81 & 9.85 & 3.57 & 10.69 & 3.10 & $24.91^{* *}$ & 0.09 & $6.08^{*}$ \\
\hline
\end{tabular}

${ }^{*}: p<0.05 ;{ }^{* * *} p<0.01$

diseases and the "purpose of life" in Japan and Thailand. A two-way ANOVA was used to assume the subordinate in the scale that measured the autonomous variable and the "purpose of life" as a dependent variable (Table 3).

As a result, interaction was significant in "attitude toward own aging "for "activities to enhance learning and culture” $(\mathrm{F}[1,430]=4.36 p<0.05)$, for “elderly persons' club activities,” $(\mathrm{F}[1,430]=6.50 p<0.01)$, “ lonely dissatisfaction," for "neighbors and friends, and socializing with acquaintances," $(\mathrm{F}[1,430]=8.66 p<0.01)$, for “care of grandchild, and family reunion”, “care of grandchild, and family reunion,”(F[1, 430] = 8.27 $p<0.01)$, “ lonely dissatisfaction” ( $\mathrm{F}[1,430]=4.76, p<0.05)$, and "Sum” $(\mathrm{F}[1,430]=5.30, p<0.05)$, “ lonely dissatisfaction " for "spouse," $(\mathrm{F}[1,430]=4.91 p<0.05)$ and "Sum” $(\mathrm{F}[1,430]=3.73, p<0.05)$, “ lonely dissatisfaction " for "child," (F[1, 430] = $6.46 p<0.05)$, and for “grandchild” $(\mathrm{F}[1,430]=8.27, p<0.01)$ and "Sum” (F[1, $430]=4.44, p<0.05)$. Regarding "attitude toward own aging” in Thailand, a significant difference was found for "Sum" $(\mathrm{F}[1,430]=9.81, p<0.01)$ and "activities to enhance learning and culture" $(\mathrm{F}[1,430]=4.80, p<$ 0.05) when each simple main effect was examined. In “elderly persons' club activities” in Thailand, a significant difference was found for "attitude toward own aging” ( $\mathrm{F}[1,430]=9.84, p<0.01)$, " lonely dissatisfaction " (F[1, $430]=8.55, p<0.01)$, and "Sum" $(\mathrm{F}[1,430]=8.66, p<0.01)$. In "neighbors and friends, and socializing with acquaintances," a significant difference was confirmed in Japan for “ attitude toward own aging ” (F[1, 430] = 5.53, $p<0.05)$, “ agitation ” $(\mathrm{F}[1,430]=5.16, p<0.05)$, “ lonely dissatisfaction ” $(\mathrm{F}[1,430]=5.59, p<0.05)$, and "Sum" $(\mathrm{F}[1,430]=8.25, p<0.01)$. Moreover, a significant difference was found for "lonely dissatisfaction" $(\mathrm{F}[1,430]=4.63, p<0.05)$ in Thailand. For "spouse," a significant difference was found for "attitude toward own aging” $(\mathrm{F}[1,430]=9.94, p<0.01)$, “ lonely dissatisfaction ” $(\mathrm{F}[1,430]=5.21, p<0.05)$, and "Sum” (F[1, $430]=6.96, p<0.01)$ in Japan. For “child," a significant difference was found for "agitation” $(F[1,430]=4.10$, $p<0.05)$ and "Sum” $(\mathrm{F}[1,430]=3.74, p<0.05)$ in Thailand. For "grandchild," a significant difference was found for "attitude toward own aging” $(\mathrm{F}[1,430]=8.94, p<0.01)$, “ lonely dissatisfaction ” $(\mathrm{F}[1,430]=8.97, p<$ $0.01)$, and "Sum" $(\mathrm{F}[1,430]=6.34, p<0.05)$ in Japan.

\subsection{Examination of the Model That Influences Elderly Persons' "Purpose of Life" by Country}

A comparative study of Model 1(event, disease $\rightarrow$ purpose of life $\rightarrow$ mental health, and IADL) and Model 2 (event, disease $\rightarrow$ mental health, and IADL $\rightarrow$ purpose of life) was undertaken to examine the model that influenced elderly persons' "purpose of life” in Japan and Thailand (Figure 1).

Model 1 was adopted as it was $\chi^{2}=67.203, d f=14$, GFI $=0.96$, AGFI $=0.91$, RMSEA $=0.005$, and AIC $=$ 123.203, while Model 2 was $\chi^{2}=86.153, d f=14$, GFI $=0.94$, AGFI $=0.88$, RMSEA $=0.007$, AIC $=150.153$ (Figure 2).

The models were compared regarding "purpose of life" in Japan and Thailand via the Simultaneous Analysis of Several Groups. Covariance structure analysis was used for Model 1. The goodness of fit of the model was excellent; this model was common to both populations and goodness of fit was strong for "purpose of life.”All path coefficients had significance levels of $5 \%$. When the difference between the groups concerning each estimated value of the model was examined, the path $(Z \geq 1.96)$ with the large difference between parameters was 
Table 3. (a) Difference between event and "purpose of life feeling” that becomes "purpose of life" by country; (b) The comparative of "the events leading to life purpose" and "purpose of life" in Japan and Thailand elderly people.

(a)

\begin{tabular}{|c|c|c|c|c|c|c|c|c|c|c|c|}
\hline & \multicolumn{5}{|c|}{ Japan } & \multicolumn{3}{|c|}{ Thailand } & \multirow[b]{3}{*}{$\begin{array}{c}\text { Main } \\
\text { effect } \\
\text { (in Japan } \\
\text { and } \\
\text { Thailand) }\end{array}$} & \multirow[b]{3}{*}{$\begin{array}{c}\text { Main } \\
\text { effect } \\
\text { (events) }\end{array}$} & \multirow[b]{3}{*}{ Interaction } \\
\hline & \multicolumn{8}{|c|}{ Work } & & & \\
\hline & \multicolumn{2}{|c|}{ Yes $(\mathrm{N}=24)$} & \multicolumn{2}{|c|}{ No $(\mathrm{N}=210)$} & \multicolumn{2}{|c|}{ Yes $(\mathrm{N}=26)$} & \multicolumn{2}{|c|}{ No $(N=174)$} & & & \\
\hline & $\mathbf{M}$ & SD & $\mathbf{M}$ & SD & $\mathbf{M}$ & SD & $\mathbf{M}$ & SD & $\mathbf{F}$ & $\mathbf{F}$ & $\mathbf{F}$ \\
\hline Attitude toward own aging & 3.25 & 1.03 & 2.90 & 1.45 & 2.35 & 1.44 & 2.26 & 1.35 & $13.67^{* *}$ & 1.10 & 0.39 \\
\hline Agitation & 4.58 & 1.79 & 4.06 & 1.78 & 3.73 & 1.59 & 3.47 & 1.40 & $8.70^{* *}$ & 2.55 & 0.29 \\
\hline Lonely dissatisfaction & 5.25 & 0.85 & 4.80 & 1.43 & 4.85 & 1.22 & 4.60 & 1.39 & 2.13 & 2.75 & 0.24 \\
\hline \multirow[t]{3}{*}{ Sum } & 13.08 & 2.43 & 11.77 & 3.89 & 10.92 & 3.54 & 10.33 & 3.24 & $11.26^{* *}$ & 3.17 & 0.46 \\
\hline & \multicolumn{8}{|c|}{ Activities to enhance learning and culture } & & & \\
\hline & \multicolumn{2}{|c|}{ Yes $(\mathrm{N}=79)$} & \multicolumn{2}{|c|}{ No $(\mathrm{N}=155)$} & \multicolumn{2}{|c|}{ Yes $(N=7)$} & \multicolumn{2}{|c|}{ No $(\mathrm{N}=193)$} & & & \\
\hline Attitude toward own aging & 3.25 & 1.32 & 2.77 & 1.44 & 3.86 & 1.57 & 2.21 & 1.32 & 0.01 & $14.48^{* *}$ & $4.36^{*}$ \\
\hline Agitation & 4.25 & 1.71 & 4.05 & 1.82 & 4.29 & 0.76 & 3.48 & 1.44 & 0.65 & 2.34 & 0.82 \\
\hline Lonely dissatisfaction & 5.01 & 1.16 & 4.77 & 1.49 & 5.14 & 1.22 & 4.62 & 1.37 & 0.00 & 1.87 & 0.25 \\
\hline \multirow[t]{3}{*}{ Sum } & 12.52 & 3.18 & 11.59 & 4.04 & 13.29 & 3.09 & 10.31 & 3.25 & 0.13 & $7.32^{* *}$ & 2.01 \\
\hline & \multicolumn{8}{|c|}{ Sports and recreational activities } & & & \\
\hline & \multicolumn{2}{|c|}{ Yes $(\mathrm{N}=86)$} & \multicolumn{2}{|c|}{ No $(\mathrm{N}=148)$} & \multicolumn{2}{|c|}{ Yes $(\mathrm{N}=5)$} & \multicolumn{2}{|c|}{ No $(\mathrm{N}=195)$} & & & \\
\hline Attitude toward own aging & 3.24 & 1.30 & 2.76 & 1.45 & 3.20 & 1.79 & 2.25 & 1.34 & 0.73 & $4.91^{*}$ & 0.51 \\
\hline Agitation & 4.16 & 1.69 & 4.09 & 1.84 & 4.40 & 0.89 & 3.48 & 1.43 & 0.23 & 1.66 & 1.20 \\
\hline Lonely dissatisfaction & 5.22 & 0.91 & 4.64 & 1.57 & 5.80 & 0.45 & 4.61 & 1.37 & 0.73 & $7.66^{* *}$ & 0.90 \\
\hline \multirow[t]{3}{*}{ Sum } & 12.63 & 3.01 & 11.48 & 4.12 & 13.40 & 2.41 & 10.33 & 3.27 & 0.05 & $6.37^{* *}$ & 1.32 \\
\hline & \multicolumn{8}{|c|}{ Hobby activities } & & & \\
\hline & \multicolumn{2}{|c|}{ Yes $(\mathrm{N}=114)$} & \multicolumn{2}{|c|}{ No $(N=120)$} & \multicolumn{2}{|c|}{ Yes $(N=26)$} & No $(\mathrm{N}$ & $=174)$ & & & \\
\hline Attitude toward own aging & 3.05 & 1.47 & 2.82 & 1.36 & 2.88 & 1.21 & 2.18 & 1.36 & $5.67^{*}$ & $7.49^{* *}$ & 1.97 \\
\hline Agitation & 4.34 & 1.67 & 3.90 & 1.87 & 3.73 & 1.40 & 3.47 & 1.43 & $6.71^{* *}$ & 3.05 & 0.21 \\
\hline Lonely dissatisfaction & 5.05 & 1.20 & 4.66 & 1.53 & 5.15 & 1.26 & 4.56 & 1.37 & 0.00 & $8.55^{* *}$ & 0.36 \\
\hline Sum & 12.45 & 3.50 & 11.38 & 3.99 & 11.77 & 3.13 & 10.21 & 3.26 & $4.45^{*}$ & $9.02^{* *}$ & 0.33 \\
\hline & & & & lunter & activiti & & & & & & \\
\hline & Yes ( & $=37)$ & No $(\mathrm{N}$ & 197) & Yes ( & $=5)$ & No $(\mathrm{N}$ & $=195)$ & & & \\
\hline Attitude toward own aging & 3.73 & 1.15 & 2.79 & 1.41 & 3.80 & 0.84 & 2.23 & 1.34 & 0.54 & $14.45^{* *}$ & 0.90 \\
\hline Agitation & 4.81 & 1.47 & 3.98 & 1.81 & 3.00 & 1.87 & 3.52 & 1.42 & $8.39^{* *}$ & 0.15 & 2.92 \\
\hline Lonely dissatisfaction & 5.41 & 0.76 & 4.75 & 1.46 & 5.60 & 0.89 & 4.61 & 1.37 & 0.01 & $6.13^{* *}$ & 0.25 \\
\hline Sum & 13.95 & 2.54 & 11.52 & 3.87 & 12.40 & 2.70 & 10.36 & 3.29 & 2.51 & $6.86^{* *}$ & 0.05 \\
\hline
\end{tabular}




\section{Continued}

\begin{tabular}{|c|c|c|c|c|c|c|c|c|c|c|c|}
\hline \multirow[b]{3}{*}{ Attitude toward own aging } & \multicolumn{8}{|c|}{ Elderly persons' club activities } & \multirow[b]{3}{*}{$4.58^{*}$} & \multirow[b]{3}{*}{$5.16^{*}$} & \multirow[b]{3}{*}{$6.50^{*}$} \\
\hline & \multicolumn{2}{|c|}{ Yes $(\mathrm{N}=49)$} & \multicolumn{2}{|c|}{ No $(\mathrm{N}=185)$} & \multicolumn{2}{|c|}{ Yes $(\mathrm{N}=32)$} & \multicolumn{2}{|c|}{ No $(\mathrm{N}=168)$} & & & \\
\hline & 2.90 & 1.30 & 2.95 & 1.45 & \multirow{2}{*}{$\begin{array}{l}2.97 \\
3.84\end{array}$} & \multirow{2}{*}{$\begin{array}{l}1.36 \\
1.39\end{array}$} & \multirow{2}{*}{$\begin{array}{l}2.14 \\
3.44\end{array}$} & \multirow{2}{*}{$\begin{array}{l}1.32 \\
1.43\end{array}$} & & & \\
\hline Agitation & 4.35 & 1.72 & 4.05 & 1.80 & & & & & $7.49^{* *}$ & 2.91 & 0.07 \\
\hline Lonely dissatisfaction & 5.16 & 0.97 & 4.77 & 1.47 & 5.28 & 0.92 & 4.51 & 1.41 & 0.16 & $11.60^{* *}$ & 1.19 \\
\hline \multirow[t]{3}{*}{ Sum } & 12.41 & 3.12 & 11.77 & 3.94 & 12.09 & 2.52 & 10.09 & 3.32 & $5.05^{*}$ & $8.91^{* *}$ & 2.37 \\
\hline & \multicolumn{8}{|c|}{ Neighbors and friends, and socializing with acquaintances } & & & \\
\hline & \multicolumn{2}{|c|}{ Yes $(\mathrm{N}=104)$} & \multicolumn{2}{|c|}{ No $(N=130)$} & \multicolumn{2}{|c|}{ Yes $(\mathrm{N}=13)$} & \multicolumn{2}{|c|}{ No $(\mathrm{N}=187)$} & & & \\
\hline Attitude toward own aging & 3.17 & 1.30 & 2.75 & 1.48 & 2.69 & 1.65 & 2.24 & 1.33 & $5.13^{*}$ & $4.07^{*}$ & 0.00 \\
\hline Agitation & 4.38 & 1.62 & 3.90 & 1.88 & 3.38 & 1.71 & 3.51 & 1.41 & $7.35^{* *}$ & 0.48 & 1.44 \\
\hline Lonely dissatisfaction & 5.09 & 0.98 & 4.66 & 1.63 & 3.85 & 1.68 & 4.69 & 1.33 & $7.90^{* *}$ & 0.94 & $8.66^{* *}$ \\
\hline \multirow[t]{3}{*}{ Sum } & 12.64 & 2.91 & 11.31 & 4.29 & 9.92 & 4.52 & 10.44 & 3.19 & $10.32^{* *}$ & 0.53 & 2.77 \\
\hline & \multicolumn{8}{|c|}{ Care of grandchild, and family reunion } & & & \\
\hline & \multicolumn{2}{|c|}{ Yes $(\mathrm{N}=38)$} & \multicolumn{2}{|c|}{ No $(N=196)$} & \multicolumn{2}{|c|}{ Yes $(\mathrm{N}=109)$} & No (I & $=91)$ & & & \\
\hline Attitude toward own aging & 3.58 & 1.18 & 2.81 & 1.43 & 2.21 & 1.43 & 2.34 & 1.27 & $34.71^{* *}$ & $4.18^{*}$ & $8.27^{* *}$ \\
\hline Agitation & 4.39 & 1.87 & 4.06 & 1.77 & 3.53 & 1.46 & 3.47 & 1.39 & $15.40^{* *}$ & 1.13 & 0.55 \\
\hline Lonely dissatisfaction & 5.32 & 0.78 & 4.76 & 1.46 & 4.58 & 1.40 & 4.70 & 1.33 & $6.49^{*}$ & 1.90 & $4.76^{*}$ \\
\hline Sum & 13.29 & 2.81 & 11.63 & 3.90 & 10.32 & 3.43 & 10.52 & 3.11 & $25.78^{* * *}$ & 3.30 & $5.30^{*}$ \\
\hline & & & going 0 & for sh & pping a & travel & & & & & \\
\hline & Yes $(\mathrm{N}$ & $=111)$ & No $(\mathrm{N}$ & 123) & Yes (1 & $=13)$ & No ( & $=183)$ & & & \\
\hline Attitude toward own aging & 3.13 & 1.29 & 2.76 & 1.50 & 2.46 & 1.13 & 2.26 & 1.37 & $7.22^{* *}$ & 1.69 & 0.13 \\
\hline Agitation & 4.15 & 1.78 & 4.08 & 1.80 & 3.54 & 1.13 & 3.50 & 1.45 & $5.39^{*}$ & 0.04 & 0.01 \\
\hline Lonely dissatisfaction & 5.09 & 1.04 & 4.63 & 1.62 & 4.77 & 1.24 & 4.63 & 1.38 & 0.58 & 1.92 & 0.52 \\
\hline Sum & 12.37 & 3.17 & 11.48 & 4.24 & 10.77 & 2.80 & 10.39 & 3.32 & $5.78^{*}$ & 1.29 & 0.20 \\
\hline
\end{tabular}

(b)

\begin{tabular}{|c|c|c|c|c|c|c|c|c|c|c|c|}
\hline & \multicolumn{5}{|c|}{ Japan } & \multicolumn{3}{|c|}{ Thailand } & \multirow[b]{3}{*}{$\begin{array}{c}\text { Main } \\
\text { effect (in } \\
\text { Japan and } \\
\text { Thailand) }\end{array}$} & \multirow[b]{3}{*}{$\begin{array}{c}\text { Main } \\
\text { effect } \\
\text { (events) }\end{array}$} & \multirow[b]{3}{*}{ Interaction } \\
\hline & \multicolumn{8}{|c|}{ Activities, such as residents' association } & & & \\
\hline & \multicolumn{2}{|c|}{ Yes $(\mathrm{N}=24)$} & \multicolumn{2}{|c|}{ No $(\mathrm{N}=210)$} & \multicolumn{2}{|c|}{ Yes $(\mathrm{N}=1)$} & \multicolumn{2}{|c|}{ No $(N=199)$} & & & \\
\hline & $\mathbf{M}$ & SD & $\mathbf{M}$ & SD & $\mathbf{M}$ & SD & $\mathbf{M}$ & SD & $\mathbf{F}$ & $\mathbf{F}$ & $\mathbf{F}$ \\
\hline Attitude toward own aging & 3.00 & 1.38 & 2.93 & 1.42 & 2.00 & 0.00 & 2.27 & 1.36 & 1.35 & 0.02 & 0.06 \\
\hline Agitation & 4.42 & 1.50 & 4.08 & 1.81 & 2.00 & 0.00 & 3.51 & 1.42 & 3.20 & 0.50 & 1.23 \\
\hline Lonely dissatisfaction & 5.08 & 1.32 & 4.82 & 1.40 & 5.00 & 0.00 & 4.63 & 1.37 & 0.04 & 0.20 & 0.01 \\
\hline Sum & 12.50 & 3.53 & 11.83 & 3.82 & 9.00 & 0.00 & 10.42 & 3.29 & 1.81 & 0.04 & 0.32 \\
\hline \multicolumn{12}{|c|}{ Accumulated knowledge and technology } \\
\hline & \multicolumn{2}{|c|}{ Yes $(\mathrm{N}=12)$} & \multicolumn{2}{|c|}{ No $(N=222)$} & \multicolumn{2}{|c|}{ Yes $(\mathrm{N}=3)$} & \multicolumn{2}{|c|}{ No $(\mathrm{N}=197)$} & & & \\
\hline Attitude toward own aging & 3.33 & 1.37 & 2.91 & 1.42 & 4.00 & 1.00 & 2.24 & 1.34 & 0.00 & $5.82^{*}$ & 2.20 \\
\hline Agitation & 4.17 & 1.85 & 4.11 & 1.78 & 3.33 & 2.89 & 3.51 & 1.41 & 1.83 & 0.01 & 0.05 \\
\hline Lonely dissatisfaction & 5.00 & 1.21 & 4.84 & 1.40 & 5.33 & 1.16 & 4.62 & 1.37 & 0.02 & 0.92 & 0.37 \\
\hline Sum & 12.50 & 3.53 & 11.87 & 3.81 & 12.67 & 4.16 & 10.38 & 3.27 & 0.33 & 1.58 & 0.51 \\
\hline
\end{tabular}




\section{Continued}

\begin{tabular}{|c|c|c|c|c|c|c|c|c|c|c|c|}
\hline \multirow[b]{3}{*}{ Attitude toward own aging } & \multicolumn{8}{|c|}{ Spouse } & \multirow[b]{3}{*}{$9.28^{* *}$} & \multirow[b]{3}{*}{0.29} & \multirow[b]{3}{*}{0.82} \\
\hline & \multicolumn{2}{|c|}{ Yes $(\mathrm{N}=34)$} & \multicolumn{2}{|c|}{ No $(N=200)$} & \multicolumn{2}{|c|}{ Yes $(\mathrm{N}=7)$} & \multicolumn{2}{|c|}{ No $(N=193)$} & & & \\
\hline & 3.03 & 1.31 & 2.92 & 1.43 & 1.86 & 1.22 & 2.28 & 1.36 & & & \\
\hline Agitation & 3.97 & 1.66 & 4.14 & 1.81 & 2.29 & 1.50 & 3.55 & 1.41 & $10.78^{* *}$ & $4.27^{*}$ & 2.49 \\
\hline Lonely dissatisfaction & 5.15 & 1.23 & 4.80 & 1.41 & 3.71 & 1.60 & 4.67 & 1.35 & $7.10^{* *}$ & 1.07 & $4.91^{*}$ \\
\hline \multirow[t]{3}{*}{ Sum } & 12.15 & 3.33 & 11.86 & 3.87 & 7.86 & 3.85 & 10.50 & 3.23 & $13.83^{* *}$ & 2.41 & $3.73^{*}$ \\
\hline & \multicolumn{8}{|c|}{ Children } & & & \\
\hline & \multicolumn{2}{|c|}{ Yes $(\mathrm{N}=34)$} & \multicolumn{2}{|c|}{ No $(N=200)$} & \multicolumn{2}{|c|}{ Yes $(\mathrm{N}=23)$} & \multicolumn{2}{|c|}{ No $(\mathrm{N}=177)$} & & & \\
\hline Attitude toward own aging & 3.59 & 1.02 & 2.82 & 1.44 & 2.35 & 1.61 & 2.26 & 1.32 & $20.60^{* *}$ & $4.58^{*}$ & 2.88 \\
\hline Agitation & 4.24 & 1.63 & 4.09 & 1.81 & 3.78 & 1.28 & 3.47 & 1.44 & $5.25^{*}$ & 0.93 & 0.14 \\
\hline Lonely dissatisfaction & 5.50 & 0.66 & 4.74 & 1.45 & 4.48 & 1.47 & 4.66 & 1.36 & $7.83^{* *}$ & 2.17 & $5.62^{*}$ \\
\hline \multirow[t]{3}{*}{ Sum } & 13.32 & 2.42 & 11.66 & 3.93 & 10.61 & 3.24 & 10.38 & 3.29 & $15.17^{* *}$ & 3.40 & 1.97 \\
\hline & \multicolumn{8}{|c|}{ Grandchildren } & & & \\
\hline & \multicolumn{2}{|c|}{ Yes $(\mathrm{N}=73$} & \multicolumn{2}{|c|}{ No $(N=161)$} & \multicolumn{2}{|c|}{ Yes $(\mathrm{N}=83)$} & \multicolumn{2}{|c|}{ No $(N=177)$} & & & \\
\hline Attitude toward own aging & 3.30 & 1.20 & 2.77 & 1.48 & 2.17 & 1.20 & 2.34 & 1.46 & $31.71^{* *}$ & 1.67 & $6.46^{* *}$ \\
\hline Agitation & 4.36 & 1.65 & 4.01 & 1.83 & 3.55 & 1.42 & 3.47 & 1.44 & $16.71^{* *}$ & 1.76 & 0.66 \\
\hline Lonely dissatisfaction & 5.22 & 1.02 & 4.68 & 1.50 & 4.64 & 1.33 & 4.63 & 1.40 & $5.24^{*}$ & $3.86^{*}$ & 3.69 \\
\hline \multirow[t]{3}{*}{ Sum } & 12.88 & 2.87 & 11.46 & 4.07 & 10.36 & 3.18 & 10.44 & 3.37 & $24.58^{* *}$ & 3.51 & $4.44^{*}$ \\
\hline & & & & & & & & & & & \\
\hline & Yes ( & $=54)$ & No $(\mathrm{N}$ & $=180)$ & Yes & $=82)$ & No $(\mathrm{N}$ & $=118)$ & & & \\
\hline Attitude toward own aging & 3.31 & 1.23 & 2.82 & 1.45 & 2.39 & 1.52 & 2.19 & 1.23 & $28.56^{* *}$ & $5.69^{*}$ & 0.98 \\
\hline Agitation & 4.11 & 1.73 & 4.12 & 1.80 & 3.55 & 1.36 & 3.47 & 1.47 & $12.19^{* *}$ & 0.04 & 0.05 \\
\hline Lonely dissatisfaction & 5.07 & 1.04 & 4.78 & 1.47 & 4.70 & 1.41 & 4.59 & 1.34 & 3.80 & 1.81 & 0.42 \\
\hline Sum & 12.50 & 3.07 & 11.72 & 3.97 & 10.63 & 3.52 & 10.25 & 3.11 & $19.59^{* *}$ & 2.36 & 0.28 \\
\hline & & & & & & & & & & & \\
\hline & Yes ( & $=18)$ & No $(\mathrm{N}$ & $=216)$ & Yes & $=1)$ & No $(\mathrm{N}$ & $=199)$ & & & \\
\hline Attitude toward own aging & 3.11 & 1.37 & 2.92 & 1.42 & 5.00 & 0.00 & 2.26 & 1.35 & 0.73 & $4.20^{*}$ & 3.20 \\
\hline Agitation & 4.06 & 1.83 & 4.12 & 1.78 & 5.00 & 0.00 & 3.50 & 1.42 & 0.04 & 0.73 & 0.87 \\
\hline Lonely dissatisfaction & 5.28 & 0.67 & 4.81 & 1.43 & 6.00 & 0.00 & 4.63 & 1.37 & 0.14 & 1.66 & 0.41 \\
\hline Sum & 12.44 & 2.20 & 11.86 & 3.89 & 16.00 & 0.00 & 10.38 & 3.27 & 0.32 & 2.85 & 1.88 \\
\hline & & & & Role in & le hom & & & & & & \\
\hline & Yes ( & $=37)$ & No $(\mathrm{N}$ & $=197)$ & Yes & $=19)$ & No $(\mathrm{N}$ & $=185)$ & & & \\
\hline Attitude toward own aging & 3.32 & 1.27 & 2.86 & 1.43 & 2.00 & 1.37 & 2.30 & 1.35 & $20.65^{* *}$ & 0.15 & 3.34 \\
\hline Agitation & 4.24 & 1.64 & 4.09 & 1.81 & 3.74 & 1.52 & 3.48 & 1.42 & $5.21^{*}$ & 0.70 & 0.05 \\
\hline Lonely dissatisfaction & 5.08 & 1.04 & 4.81 & 1.44 & 4.32 & 1.42 & 4.67 & 1.36 & $4.76^{*}$ & 0.04 & 2.29 \\
\hline Sum & 12.65 & 2.97 & 11.76 & 3.91 & 10.05 & 3.44 & 10.45 & 3.27 & $13.34^{* *}$ & 0.21 & 1.44 \\
\hline & & & & Role ir & society & & & & & & \\
\hline & Yes & $J=6)$ & No $(\mathrm{N}$ & $=228)$ & Yes & $=4)$ & No $(\mathrm{N}$ & $=196)$ & & & \\
\hline Attitude toward own aging & 3.67 & 1.03 & 2.92 & 1.42 & 2.75 & 1.71 & 2.26 & 1.35 & 3.02 & 1.88 & 0.08 \\
\hline Agitation & 4.50 & 1.38 & 4.11 & 1.79 & 3.25 & 1.26 & 3.51 & 1.43 & 3.01 & 0.02 & 0.38 \\
\hline Lonely dissatisfaction & 5.50 & 0.55 & 4.83 & 1.40 & 4.25 & 1.26 & 4.64 & 1.37 & 2.56 & 0.09 & 1.38 \\
\hline Sum & 13.67 & 2.07 & 11.86 & 3.81 & 10.25 & 2.22 & 10.41 & 3.30 & $4.36^{*}$ & 0.50 & 0.72 \\
\hline
\end{tabular}

${ }^{*}: p<0.05 ;{ }^{* *} p<0.01$. 


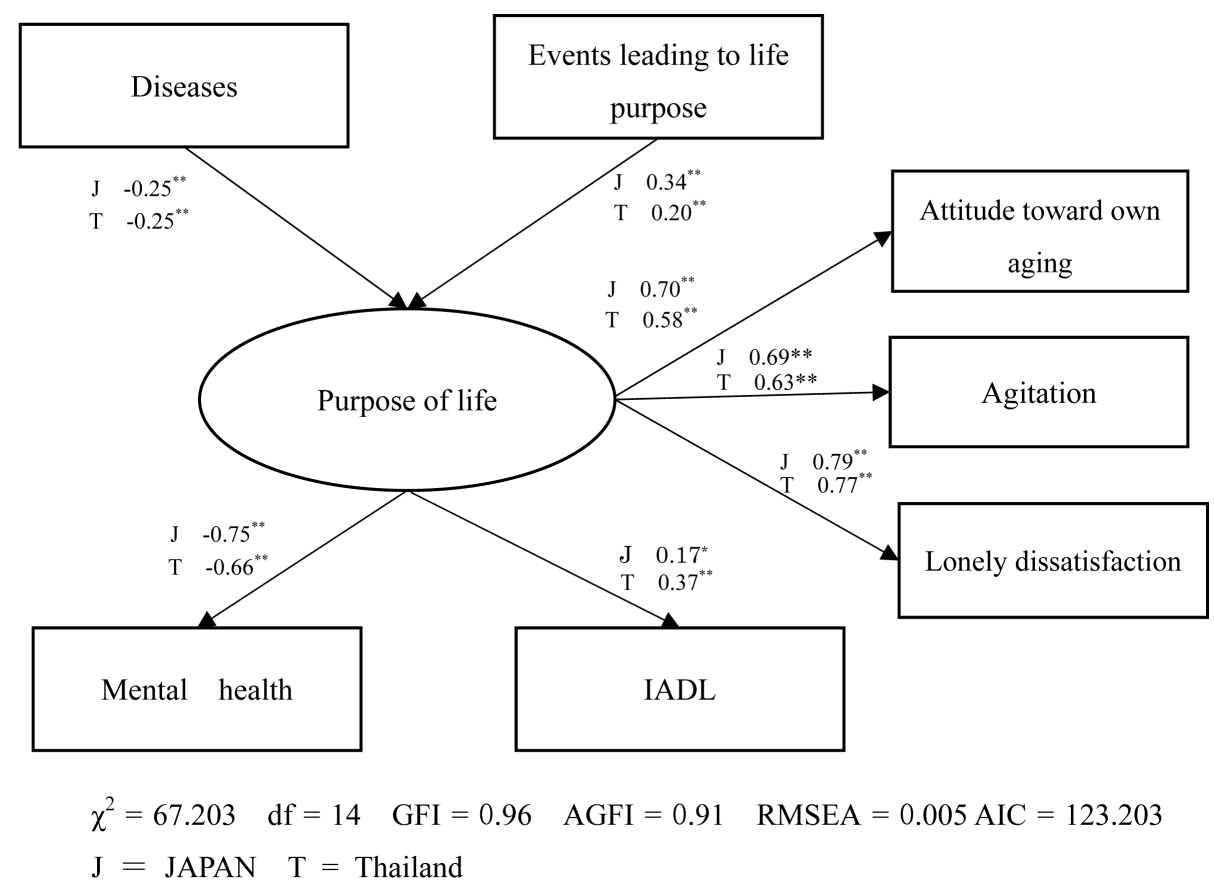

Figure 2. Models of factors related to older adults’ purpose of life.

"purpose of life" $\rightarrow$ "mental health" $(\mathrm{Z}=2.431)$; Thailand $(\beta=-0.66)$ drove "purpose of life" $\rightarrow$ "mental health" significantly lower than Japan $(\beta=-0.75)$.

\section{Discussion}

\subsection{Factors That Influence the "Purpose of Life" by Each Country}

In the base attribute and condition of participants, by country, there were many "spouse with two livelihoods" in Thailand and "three-person households" in Japan. Japan begins to be changing because of the growing numbers of nuclear families. Such a large difference could not be found in any other comparative study.

Regarding differences between Japan and Thailand and "purpose of life" according to sex, Japanese men scored higher than Japanese women in "agitation" and "Sum." For "lonely dissatisfaction," Thai women had higher scores compared to Thai men. Kondo and Kamada reported that men's "purpose of life" decreased as they aged and was lower compared to women [22]. However, Yamashita et al. were reported no effect of sex; therefore, no consistent view exists [23]. According to Harada et al, the reasons for elderly Japanese men not undertaking entertainment include "no friend." [24]. In this study, it was thought that the "purpose of life" was high for Japanese men as it targeted elderly persons who meet at the public hall in Japan. This study came to correspond with Kondo and Kamada's study in Japan, which examined elderly persons' "purpose of life." [22]. Furthermore, sex was not found to be important in Thailand.

It was suggested that "activity to improve study and education" and "associations with neighbors, friends, and acquaintances" were activities in Japan and Thailand that improved the "purpose of life," which then became the "purpose of life." Moreover, "elderly persons' club activities" and "child" were effective in Thailand, and "spouse" and "grandchild" were effective in Japan.

The two countries both had high scores when it came to participation in elderly persons' club activities. Japan focuses more on hobbies associated with personal interest and ability, while Thailand focuses more on participation in volunteer group activities. While people may not want to participate, "neighbors, friends, and acquaintance scan help increase learning and culture," and participation in "elderly persons' club activities" [25]. However, the meaningfulness for "elderly persons' club activities" was not confirmed, probably because Japanese elderly persons did not enjoy the places where most people gathered. Sugiyama et al discussed factors involved in helping one to be conscious of the definite aim; these included "participation in older persons' clubs" and "being with another person." [26]. The findings suggest the importance of Thai elderly's good practice on food 
habits, regular exercise, seeking knowledge toward health, religious activity involvement, good relationships with others, and well-planned income and expenses resulting in life satisfaction [27]. Buraskorn et al. suggested "clubs for the elderly" as effective in improving "purpose of life feeling" in Thailand [28]. A comparable result was obtained in the present study. Thais have very positive welcomes, usually greeting people with a smile, even if it is the first time they are meeting. "Elderly persons' club activities" are group activities that can contribute to a "purpose of life." Yagi et al. investigated elderly people belonging to Japanese elderly persons' clubs and those with a definite aim in life comprised 94.5\% [29]. Living with challenge, curiosity, and new, positive things were important; therefore, group activities are effective for the improvement of the "purpose of life feeling.”The intention to participate in group activities via "elderly persons' club activities" is thought to be necessary for people who are not part of a social system.

Regarding "child,"“spouse," and "grandchild," these influence family structure. In Thailand, there were mostly "three-person households"; in Japan, households were mostly comprised of "a spouse and two livelihoods."Because of this, in Japan, the relationship to "spouse" was related to "purpose of life."Furthermore, for Japanese elderly people, a husband has a negative effect on elderly woman, while a wife who is not different from the husband in terms of resilience and life satisfaction has an equal effect when compared to the existence of a woman he has children with or does not have children with [30] [31]. Therefore, "spouse" was high in Japan regarding "purpose of life." In addition, the existence of a grandchild living together has an equal effect on "a feeling of a definite aim." Sugii and Motomuranote that living together with a single child has a reliably negative effect [32]; however, Maeda states that Japanese elderly persons consider adulthood in terms of "I have a restriction-like relationship." [33]. Therefore, a significant difference was found to not be good for the "child" at confirmation in Japan, and a significant difference was good for the "grandchild" at confirmationin Thailand. Meanwhile, a significant difference was found for the "child" in Thailand. Thanakwang et al. report relevancy with especially strong family support; "purpose of life" and the family's support have a strong relationship with "purpose of life." [34]. Their study investigated elderly persons in Thailand in terms of family support and friendship. There were many "three-person households" in the base attribute in Thailand. According to Knodel and Chayouan, more than $70 \%$ of elderly people aged 60 years or older live with their child [35]. The child's revenue becomes a major revenue source for elderly persons in Thailand [36]; 52.3\% of the revenues of the elderly persons in Thailand involve revenue from the child [37]. Therefore, there appears to be a trend regarding "purpose of life" and "child" for elderly persons in Thailand.

The percentage of couple-only households or solitary households aged over 60 years was $53.6 \%$ (65 years in Japan) in Japan and was $16.8 \%$ for males, $21.3 \%$ for females in Thailand [38] [39]. In Japan, the elderly must change from staying with to living near their children [40]. Houses for elderly persons who do not become constrained in their dealings with their child should cohabit if necessary as the family structure affects elderly persons' "purpose of life feeling" in Japan.

As mentioned above, an exchange between the relationship with an elderly persons' family and a positive generation was suggested; it was considered important in the improvement of "purpose of life."

\subsection{Examination of a Model That Influences Elderly Persons' "Purpose of Life" by Country}

First, Model 1 (event, disease $\rightarrow$ purpose of life $\rightarrow$ mental health, and IADL became purpose of life) was adopted. It is reported that factors, such as self-efficacy and self-esteem, exist between the physical exercise activities involving movement, sports, and so on, and health-related QOL [41]-[43]. In this study, "a feeling of definite aim" intervened between "an event to become purpose of life,"“a disease,"“ADL," and "mental health."For Aoki, mental health and physical activity moved toward a feeling of definite aim [44]; however, in this study, a feeling of definite aim raised mental health and, therefore, the model in which ADL improved was adopted. "Purpose of life feeling" appears to increase by having an "event that becomes purpose of life," and preventing "disease."This leads to improvements in elderly persons' "mental health" and "ADL" in both countries.

In Thailand and Japan, which experience advanced aging, the model that was adopted determined that the "preventive approach in long-term care" leads to a much longer lifespan in the future. Even for the prevention of geriatric syndromes, such as frailty, an event can be a purpose in life, as there is a need to prevent disease. In Thailand, disease prevention and health promotion are advanced for each person in the 30 baht system, as well as Japan, based on the law concerning securing the medical care of elderly people. Reports suggest little influence on mental health because of the influence of the aged state that ADL has on mental health [45]. This view 
was favored in this model because a significant path was found. In this model, "Purpose of life feeling" improved with the event (for instance, elderly persons' club activities, and so forth) that a "purpose of life," in addition to health promotion, saw the disease prevented, and both mental health and ADL improve.

Thailand had high trends in mental health and ADL compared to Japan. In Thailand, when receiving a guest for the first time, the welcome and address involves much smiling. Overall mental health is higher compared to Japan. The burden of work in daily life, attenuation of role consciousness, and loss of "purpose of life" are easy causes of declines in mental health, while interpersonal conflict with cohabitating family does not easily cause declines, but there is the possibility of an increased depressive state [46]. Thailand's family structure is thought to be mainly comprised of a three-person household, and this difference in family structure may have had a bearing on the results.

\subsection{Combining the Present Study}

This study focused on the "purpose of life" and compared Thailand and Japan regarding the various factors related to elderly persons' "purpose of life". Regarding an "Events Leading to Life Purpose”, it was suggested that "activities to improve study and education" and "association with neighbors, friends, and acquaintances" helped both in Japan and Thailand. Moreover, "elderly persons' club activities" and "child" were effective in Thailand, while "spouse" and "grandchild" were effective in Japan. Influence, social background, and so forth regarding family structure affect the social system, undertaking "elderly persons' club activities" for the "purpose of life" improvement is important for those in Japan. The significance of the exchange between the relationship to elderly persons' family and positive generation was suggested. Model 1 (event, disease $\rightarrow$ purpose of life $\rightarrow$ mental health, and IADL) for both countries was adopted. In order to improve older adults' mental health and ADL by improving "purpose of life", it is required to increase the events leading to life purpose and to prevent illness for both countries. In particular, "activities to enhance learning and culture" and "neighbors and friends, and socializing with acquaintances" were the activities which raised "purpose of life". Then, "elderly persons' club activities" and "child" were effective in Thailand, while "spouse" and "grandchild" were effective in Japan.

\section{Sources of Funding}

This study was supported by the Committee for international exchange, Hyogo University and Mahasarakham University in 2014.

\section{Disclosure}

The authors have not potential conflicts of interest to disclose.

\section{References}

[1] UNFPA and Help Age International (2012) Ageing in the Twenty-First Century: A Celebration and a Challenge. 21-23.

[2] Oizumi, K. (2007) Oiteyuku Asia, Chuko Shinsho. Tokyo. (In Japanese)

[3] Global Age Watch Index (2014) Insight Report Published by Help Age International.

[4] Croissant, A. (2004) From Transition to Defective Democracy. Mapping Asia Democratization. Democratization, 11, 156-178.

[5] Cabinet Office of Japan (2008) White Paper on the National Lifestyle 2008. Prospects for Consumer Citizenship toward a Comfortable and Mature Society.

[6] Mori, S. (2000) Koureisha no ikigai (Ikigai for the Elderly). The Annuals of Sociology, 41, 15-29. (In Japanese)

[7] Egami, W. (2000) The Family, Community and Ikigai (Reason(s) for Living) in Elderly People. The Annuals of Sociology. Shakaigaku nenshi, 41, The Waseda Sociological Society.

[8] Sugiwara, H. and Akiyama, H. (2001) Social Participation of Older Adults in the Workplace and in the CommunityA Comparison of Japan and the United States. The monthly Journal of the Japan Institute of Labour, 43, 20-29.

[9] Takahashi, Y. and Wada, S. (2001) Sociology of Meaning of Life, What Is the Happiness in an Aged Society? Kobundo, Tokyo. (In Japanese)

[10] Kamiya, M. (1980) On the Meaning of Life in Japanese. Misuzu Shobo, Tokyo. 
[11] Koyano, W. (1983) Effect of Social Activity upon Morale in the Elderly. Journal of Social Gerontology, 17, 36-49.

[12] Larson, R. (1978) Thirty Years of Research on the Subjective Well-Being of Older Americans. Journal of Gerontology, 33, 109-125. http://dx.doi.org/10.1093/geronj/33.1.109

[13] Maeda, D., Asano, H. and Taniguchi, K. (1979) Roujin no shukanteki koufukukan no kenkyu (Study ofPsychological Well-Being for the Elderly: The Trial of Measurement by a Morale Scale). Tokyo Metropolitan Institute of Gerontolog, 11, 15-31. (In Japanese)

[14] Hasegawa, A., Fujiwara, Y., Hoshi, T. and Shinkai, S. (2003) Regional Differences in Ikigai (Reason(s) for Living) in Elderly People-Relationship between Ikigai and Family Structure, Physiological Situation and Functional Capacity. Japanese Journal of Geriatrics, 40, 390-396. http://dx.doi.org/10.3143/geriatrics.40.390

[15] Hasegawa, A., Fujiwara, Y. and Hoshi, T. (2001) The Review of Ikigai on the Relationship of Ikigai and Well-Being in the Elderly. Comprehensive Urban Studies, 75, 147-170.

[16] Lawton, M.P. (1975) The Philadelphia Geriatric Center Morale Scale: A Revision. Journal of Gerontology, 30, 85-89. http://dx.doi.org/10.1093/geronj/30.1.85

[17] Okuzumi, H., Furuna, T., Nishizawa, S. and Sugiura, M. (2000) Relationship between Magnitude of Body Sway and Competence in Older Persons Living in a Community. Equilibrium Research, 59, 130-135.

[18] Golderberg, D. and Williams, P. (1988) A User's Guide to the General Health Questionnaire. NFER-Nelson, Windsor.

[19] Niiro, M. and Mori, T. (2001) Investigation of the Reliability and Validity of the Japanese Version of General Health Questionnaire (GHQ-12) (Japanese). Seishin Igaku, 43, 431-436.

[20] Nilchaikovit, T., Sukying, C. and Silpakit, C. (1996) Reliability and Validity of the Thai Version of the General Health Questionnaire. Journal of the Psychiatric Association of Thailand, 41, 2-17.

[21] Lawton, M.P. and Brody, E.M. (1969) Assessment of Older People: Self-Maintaining and Instrumental Activities of Daily Living. The Gerontologist, 9, 179-186. http://dx.doi.org/10.1093/geront/9.3_Part_1.179

[22] Kondo, T. and Kamada, J. (2004) The Sex and Age Differences in the Determinants of the Feeling That Life Is Worth Living among the Aged. Japanese Journal of Geriatric Psychiatry, 15, 1281-1290.

[23] Yamashita, T., Kondo, K., Tanaka, T., et al. (2001) Sisetu koureisha no ikigai to QOL no kanren ni tuite (The Relation of Institution Elderly People's Purpose of Life and QOL). Journal of Health and Welfare Statistics, 48, 12-19.

[24] Harada, T., Kato, K., Oda, Y., Uchida, H. and Ohno, T. (2011) Daily Habits of the Elderly (II): Recreational Activities and Feeling of Life. Journal of Nagoya Bunri University, 11, 27-33.

[25] Cabinet Office, Government of Japan (2008) White Paper on the National Lifestyle in Japanese [Kokumin Seikatsu Hakusho]. Cabinet Office, Government of Japan, Tokyo.

[26] Sugiyama, Y., Fukui, I., Takekawa, T. and Inada, H. (1998) Rounenki no shakaitekiou ni eikyousuru sinritekiyouin (The Psychological Factor Influencing the Social Adaptation in Old Age). Japanese Journal of Geriatric Psychiatry, 9, 364-371. (In Japanese)

[27] Othaganont, P., Sinthuvorakan, C. and Jensupakarn, P. (2002) Daily Living Practice of the Life-Satisfied Thai Elderly. Journal of Transcultural Nursing, 13, 24-29. http://dx.doi.org/10.1177/104365960201300105

[28] Buraskorn, T. and Soparth, P. (2013) Impact of the Elderly Club on the Social Well-Being of the Rural Elderly in the Northeastern Region of Thailand. Article First Published Online, 11.

[29] Yagi, T., Takauchi, H. and Ito, M. (1991) Meaning of Life and Sport of Elderly People Living in Kyoto, Japan. Report of Research Center in Physical Education, 19, 212-217. (In Japanese)

[30] Nobe, M. (1999) The Sense of Well-Being of Elderly Women in a Medium-Size Japanese City. Sociological Theory and Methods, 14, 105-123. (In Japanese)

[31] Koyano, W. (1992) Dantiroujin niokeru moraru to shakaikannkei (Morale and Social Relationship in the Elderly People Who Live in a Housing Complex-The Moderate Effects of the Existence of a Gender and a Spouse). Tokyo Metropolitan Institute of Gerontology, 35, 3-9. (In Japanese)

[32] Sugii, J. and Motomura, H. (1992) A Study on the Subjective Well-Being of Elderly-In Relation to the Structural Components of the Family System. Japanese Journal of Family Sociology, 4, 53-65. (In Japanese)

[33] Maeda, N. (1988) Ronen-ki no yujin kankei (Friendships in Old Age). Social Gerontology, 28, 58-70. (In Japanese)

[34] Thanakwang, K., Ingersoll-Dayton, B. and Soonthorndhada, K. (2012) The Relationships among Family, Friends, and Psychological Well-Being for Thai Elderly. Aging \& Mental Health, 16, 993-1003. http://dx.doi.org/10.1080/13607863.2012.692762

[35] Knodel, J. and Chayouan, N. (2008) Population Ageing and the Well-Being of Older Persons in Thailand. Population Studies Center Research Report 08-659. 
[36] Zimmer, Z. and Amornsirisomboon, P. (2001) Socioeconomic Status and Health among Older Adults in Thailand: An Examination Using Multiple Indicators. Social Science \& Medicine, 52, 1297-1311. http://dx.doi.org/10.1016/S0277-9536(00)00232-X

[37] Knodel, J. and Chayovan, N. (2009) Older Persons in Thailand: A Demographic, Social and Economic Profile. Ageing International, 33, 3-14. http://dx.doi.org/10.1007/s12126-009-9025-8

[38] United Nations (2012) Department of Economic and Social Affairs, Population Division "Population Ageing and Development”.

[39] Ministry of Health, Labour and Welfare (2013) Outline of Health, Labour and Welfare Statistics in Japan. Statistics and Information Department Minister's Secretariat Ministry of Health, Labour and Welfare, 27. http://www.mhlw.go.jp/toukei/youran/aramashi/all.pdf

[40] National Institute of Population and Social Security Research 2011, National Institute of Population and Social Security Research in Japan (2015) The Financial Statistics of Social Security in Japan FY2012. (In Japanese)

[41] Robert, W.M., Edward, M., Erin, M.S. and Rachael, C.G. (2009) Physical Activity and Quality of Life in Multiple Sclerosis: Intermediary Roles of Disability, Fatigue, Mood, Pain, Self-Efficacy and Social Support. Psychology, Health \& Medicine, 14, 111-124. http://dx.doi.org/10.1080/13548500802241902

[42] Biddle, S.J.H. and Mutrie, N. (2008) Psychology of Physical Activity: Determinants, Wellbeing and Interventions. 2nd Edition, Routledge, London.

[43] Elavsky, S., McAuley, E., Motl, R.W., Konopack, J.F., Marquez, D.X., Hu, L., et al. (2005) Physical Activity Enhances Long-Term Quality of Life in Older Adults: Efficacy, Esteem, and Affective Influences. Annals of Behavioral Medicine, 30, 138-145. http://dx.doi.org/10.1207/s15324796abm3002_6

[44] Aoki, K. (2015) Association among Personality Traits, Factors Related to Ikigai-Kan and Ikigai-Kan of the Elderly Living at Home. Archives of Yamaguchi Prefectural University, 8, 7-17. (In Japanese)

[45] Koyano, W. (1996) Measurement Instruments for Quality of Life (2). Japanese Journal of Geriatric Psychiatry, 7, 431-441.

[46] Maeda, M. and Sato, S. (2004) Tansin koureisha no kakaeru mondai(The Issue of Isolated Elderly People). Japanese Journal of Geriatric Psychiatry, 15, 162-168. 